\title{
STRATEGIC PLANNING FOR MOBILE SERVICES ADOPTION AND DIFFUSION:
}

Empirical evidence from the Danish market

\author{
IOANNA D. CONSTANTIOU, JAN DAMSGAARD and LARS KNUTSEN \\ Department of Informatics, Copenhagen Business School
}

\begin{abstract}
This paper investigates mobile services adoption, diffusion and usage patterns in the Danish market. A similar empirical research was conducted during 2001 in Finland, Germany and Greece when mobile services were first introduced. This paper explores the impact of a set of attributes identified on that research in a more mature market context. Our objective is to confirm or reject and possibly expand the attributes that affect consumer behaviour in the long run, highlight the differences due to market evolution and observe the specific socio-economic characteristics of Danish market. We use an online survey that is based on the earlier research, but has been elaborated to address specific Danish market characteristics (e.g. the recent introduction of $3 \mathrm{G}$ services). The preliminary results offer indications on the evolution path of mobile services' market and highlight the accelerating adoption of mobile services.
\end{abstract}

Key words: mobile services; adoption and diffusion patterns; service usage; mobile shoppers.

\section{INTRODUCTION}

The availability and the plurality of mobile services are growing at a rapid pace in most countries around the world. As a stream of observations pertaining to the troubles of WAP, consecutive revisions of world $3 \mathrm{G}$ diffusion forecasts, and slow actual $3 \mathrm{G}$ uptake have emerged, scholars and practitioners have emphasized that technological advances and service availability do not automatically lead to widespread adoption and use (Baldi \& Thaung, 2002; Funk, 2001). Moreover, in roadmaps for future research there are repeated suggestions that more efforts should be made at 
understanding issues and factors explaining adoption, acceptance and use of mobile services (Lyytinen \& Yoo, 2002; Urbaczewski, Wells, \& Sarker, 2002).

Most of the traditional diffusion of innovation literature (Rogers, 1995) would argue that the greatest benefits from a service belong to the first adopters and while the adoption proceeds, the relative advantage of being an early adopter diminishes. Moreover, traditional diffusion of innovation literature argues that latter argument is prominent in case of a company, which cannot sustain a competitive advantage based on a single technology, since others will imitate it and consequently achieve a similar advantage.

We argue that for mobile services the same logic cannot be readily applied. The greatest benefits from mobile services often come after their widespread adoption. For instance, in case of SMS, its value increases as the number of adopters increases due to network externalities. Most services become more readily available and better developed as the customer base increases. We have some indications from earlier studies of mobile services on the main attributes pertaining to adoption and diffusion. In this study we seek to confirm, reject and expand these factors by building a survey that incorporates earlier findings with current knowledge and local characteristics. In particular, we provide insight on the following question:

What factors explain and predict users' adoption and diffusion of mobile services?

The adoption of mobile services is not random. We believe that there is a certain order in which services are adopted and appropriated. Thus, the adoption trajectory forms a path that evolves under the influence of specific factors. By investigating the key attributes affecting adoption, diffusion and usage of mobile services it is possible to identify behavioural patterns pertaining to the specific market. The key players may use such patterns as an insight in strategic planning that enables them to increase their market share and maximise their profits. While the recent trends of GPRS services adoption are ambiguous, we witness that the use of some independent services (e.g. MMS) is increasing rapidly. On the contrary, transactional services, have not yet reached a critical mass of users.

This paper is organized as follows. Section 2 offers a brief review on related theoretical work to consumer behaviour of electronic and mobile business and highlights the results of a previous survey with similar objectives as well as the market trends of Danish mobile communications market. Section 3 presents the research methodology used, the demographic characteristics of the sample and the hypothesis tested. Section 4 presents part of the preliminary results and addresses the research question set. 
Finally, section 5 concludes by underlining the main results and highlighting future research directions.

\section{CONSUMERS' REACTIONS TO INNOVATIVE MOBILE SERVICES}

\subsection{Research in consumer behaviour of electronic and mobile business}

Reviewing the business to consumer (B2C) e-commerce literature, it is clear that the majority of research efforts have focused on the Internet, rather on mobile telephony. As noted by Anckar \& D'Incau (2002), our understanding of the real value-adding elements in mobile business is limited, in particular "the consumers' actual reasons - the primary drivers for adopting and intending to adopt mobile services remain unclear". However, mobile business dynamics generate challenging research questions that enable building new theoretical frameworks as well as investigate managerial implications and emerging business opportunities.

Besides, B2C e-commerce, independent of the access device (e.g. PC, or mobile phone), has for any product, or service offering one generic but crucial objective: to satisfy consumers, create value and build strong relationships (Grönroos, 1997; Ravald \& Grönroos, 1996) that are characterized by high level of loyalty, return patronage and bi-directional enthusiasm. In pursuit of in depth understanding, investigating consumer needs, wishes, preferences, attitudes, characteristics, and behaviours related to current and anticipated mobile phone use becomes invigorating for strategizing, development efforts and marketing. It is the authors' position that user surveys, constitutes a reliable method, which is particularly applicable when the purpose is to generate market data for comparison among broader categories of a population. Moreover, careful generation, dissemination and responsiveness of and to adequate survey data, can also guide organizations towards increased market orientation which in turn is connected to higher levels of organizational performance (Jaworski, Kohli, \& Sahay, 2000; Jaworski \& Kohli, 1993; Slater \& Narver, 2000) and innovation (Baker \& Sinkula, 2002; Han, Kim, \& Srivastava, 2002; Hurley $\&$ Hult, 1998). Thus, current and future needs, existing consumers are a constituent group of significant importance in providing guidelines for the development of marketing and innovation strategies.

Online markets (either accessible through the PC, mobile phones or other wireless devices) constitute a channel for exchange which requires fundamental alterations in the purchasing behavior among customers. Therefore, a key task for e- and m-business is to find out who the actual and 
potential customers are (Turban et al. 1999). Along the same lines, Petrison et al. (1997) support that thorough knowledge of consumer behaviour, coupled with advances in technology, enable marketers to target customers on a more personalised, customised and segmented basis. However, consumer behaviour in mobile commerce has not yet been the subject of much research (Anckar et al., 2002; Pedersen, Methlie, \& Thorbjørnsen, 2002).

The present study aims to contribute in the understanding of consumer behaviour in case of mobile services. To accomplish this aim we offer insight on consumer attitudes and behaviours towards mobile services based on the preliminary results of a survey.

\subsection{The results of the previous survey}

A study conducted in Finland, Germany and Greece as part of the MobiCom project (Vrehopoulos et.al. 2002, 2003) recorded the attitudes and perceptions of Internet and mobile telephony users in terms of new technology and services in mobile business (such as WAP, GPRS, purchases via mobile, etc). The study was based on a survey that was addressed to a self-selected sample of Internet users. This sample is representative of the most active segment of the market with respect to the adoption and use of new technologies. Among the survey findings, the cost of service, the the value of content and usability of the device emerged as key determinants of mobile commerce adoption and use. The latter determinant is also supported by Siau and Shen (2003). The survey led to important conclusions regarding the determinants of growth, the existing impediments as well as indications for appropriate strategic businesses responses.

In particular, besides the "killer-application" SMS, there were very few services used at a significant level. Among these services were information services (e.g. brokers) and mobile banking. Mobile services were mainly adopted due to their always and anywhere availability and the increased comfort they provided. New mobile services were diffused through social networks mainly by friends and colleagues. The Internet also played an important role as an information channel in the diffusion process. This finding was also supported by earlier research indicating that virtual communities might play a vital role in catalyzing mobile service use (Rheingold, 2003), (Kim, 2000).

The high access price was considered the main deterrent for adoption of new services. It is important to remind the reader that during 2001, data services in mobile devices were mainly supported by WAP. Moreover, high access prices might be attributed to the oligopolistic structures of the respective mobile operators' markets at that time. However, the survey results also indicated that mobile users were able to differentiate between the 
inflated connection fees and the charges for the actual mobile services. While the former were perceived as rather high, the latter were perceived as relatively low priced. Moreover, the key attributes affecting mobile services' market evolution were:

- Ease of use interface,

- Security,

- Customer service,

- Price,

- Personalization,

- Comfort of device.

\subsection{The Danish market}

The Danish market for mobile telephony and services has been chosen for the purpose of this research due to its considerable maturity vis-à-vis the other markets investigated in the previous survey. For instance, GPRS services have increasingly diffused and $3 \mathrm{G}$ services have recently been launched. This market context is expected to offer indications and generate insight on the attributes of mobile market evolution path.

In terms of operators, the Danish mobile telecommunications market can be characterized as an oligopoly where five key market players (TDC, Sonofon, Telmore, Orange, and Telia) are dominant. Despite the high concentration and oligopoly nature, this market exhibits high price competition, which can be attributed to specific market characteristics. First, new entrants (Telmore, CBB Mobile and Debitel) can purchase services from incumbent mobile operators and resell them to end users. These players operate in low cost margins and drive prices of communication services at lower levels. In addition, mobile operators are jostling to capture the segment of "younger" users and to stimulate demand for new mobile services (e.g. $3 \mathrm{G}$ video services and MMS). As these users have grown accustomed to the low prices on SMS and voice calls, this has generated a "mirroring effect" to the prices on MMS and $3 \mathrm{G}$ services. For example, extensive campaigns were launched during 2003 offering MMS for free; and for signing up to new $3 \mathrm{G}$ services, mobile users could obtain three months of unlimited and free access to most of the new mobile content offered by the mobile operator 3 .

The demand side of Danish mobile communications market during 2003 showed high growth rates in terms of GPRS data transfer, SMS usage as well as MMS adoption. Statistics ${ }^{6}$ reveal that the average 290,000 GPRS subscribers generated approximately $2.74 \mathrm{MB}$ of traffic during the second 
half of 2003. Comparing the first and second half of 2003, there was an increase of $105 \%$ in the number of GPRS subscribers that drove an increase of $145 \%$ in the download/upload GPRS rate. More impressively, the average mobile phone user sent more than 515 SMS in the second half of 2003. This is a $63 \%$ increase from the first half of 2003. Although the MMS rates are bleach vis-à-vis the SMS rates, the growth rates are not. From the some 500 000 MMS being sent over the Danish mobile infrastructure during the first half of 2003, this had increased by $355 \%$ to approximately 2,3 million MMS sent during the second half. It is also worth noting that the total minutes of voice calls placed from mobile networks increased some $10.4 \%$ during this period, while the corresponding numbers on fixed networks dropped $9 \%$.

\section{METHODOLOGY AND SAMPLING}

\subsection{The Survey instrument}

The survey instrument was first developed in English and then translated into Danish. It was pilot tested using the staff of a university department (25) where $50 \%$ had prior experience on mobile services usage. The questions were revised based on their feedback. Following the revision, the survey was launched on the Internet by utilizing an online software tool (SurveyMonkey ${ }^{7}$ ). The survey will run in Denmark from February to March 2004.

Miller and Dickson (2001) argue that on-line consumer behaviour research presents a new area of academic study in marketing. They also note that most of the work in this area has been done by practitioners and strongly encourage further academic research and learning from the data of on-line research. With 50.4 internet subscriptions per 100 inhabitants and Denmark being a leading nation in terms of e-commerce ${ }^{8}$, the Internet was considered an appropriate medium for the survey as we aimed to obtain responses by users with experience of mobile phones, mobile services, and Internet services.

The survey instrument included questions on mobile communications' statistic, general demographics, mobile services adoption and diffusion processes, mobile services usage behaviour as well as Internet services usage behaviour and $3 \mathrm{G}$ services adoption process. Mobile users behaviour and usage patterns are investigated through eleven questions that include basic

\footnotetext{
${ }^{7}$ www.surveymonkey.com

${ }^{8}$ http://edition.cnn.com/2004/TECH/internet/04/20/world.online.ap/index.html
} 
issues such as the use of more elevated services than SMS, knowledge on new technological solutions available in the market, but also more advanced issues such as the frequency of use for specific mobile services. Moreover, respondents are asked to reveal extent to which they agreed/disagreed with the key attributes that were identified in the previous survey. The items are rated by respondents on a scale of 1-5, where 1 represented "strongly disagree" and 5 "strongly agree". Furthermore, in this survey we investigate $3 \mathrm{G}$ services adoption process by collecting information on possession of a 3G mobile device, current usage pattern and preferences for existing services.

Finally, as an incentive we offered the respondents a chance to participate in the lottery of two popular mobile phones currently sold in the Danish market. We acknowledge that the incentive may attract early adopters that are interested in new technologies but may also decrease the quality of responses since some respondents may take part on the survey only to win the prize. The high number of respondents that already posses a similar device with the one offered in the lottery, lowers the negative impact of this effect.

\subsection{The sampling}

The sample size is influenced by Internet and mobile penetration as well as the advertising effort for the online survey. The sample is not representative of the total Danish population since it includes self-selective Internet users. However, the intense advertising campaign and the balanced mix of internet pages hosting links to the survey (e.g. information portal, and university website) have counterbalanced part of this shortcoming. Convenience sampling was used. The current sample size is comprised of 722 Internet users. According to Hair et al. (2000) and Kinnear and Taylor (1996), convenience sampling is suitable for the requirements of exploratory research designs like the present one. The demographic characteristics of respondents are presented in Table 1.

Table 1. Demographic Characteristics of the Samples

\begin{tabular}{|c|c|c|}
\hline Demographic Categories & Range/Category & $\%$ \\
\hline \multirow{4}{*}{ Age Groups } & $18-31$ & 64,2 \\
\hline & $32-40$ & 20,4 \\
\hline & $41-64$ & 14,2 \\
\hline & $65+$ & 1,2 \\
\hline
\end{tabular}


Table 1. (continued)

\begin{tabular}{|c|c|c|}
\hline Demographic Categories & Range/Category & $\%$ \\
\hline \multirow{2}{*}{ Gender } & Male & 49,3 \\
\hline & Female & 50,7 \\
\hline \multirow{4}{*}{$\begin{array}{l}\text { Household Size (i.e. no. of } \\
\text { members) }\end{array}$} & 1 & 30,9 \\
\hline & 2 & 35,7 \\
\hline & 3 & 11,9 \\
\hline & $4+$ & 21,3 \\
\hline \multirow{5}{*}{$\begin{array}{l}\text { Monthly Gross Income of } \\
\text { Household (in Euros) }\end{array}$} & $0-1000$ & 20,2 \\
\hline & $1001-2000$ & 18,1 \\
\hline & $2001-3250$ & 13,5 \\
\hline & $3251-5000$ & 12 \\
\hline & $5000+$ & 36 \\
\hline \multirow{4}{*}{ Education } & Below High School Degree & $\overline{6,7}$ \\
\hline & High School Degree & 17,7 \\
\hline & College/University & 45 \\
\hline & Postgraduate & 30,6 \\
\hline \multirow{11}{*}{ Occupation } & Employed in the commercial sector & 5,8 \\
\hline & Executive / manager & 3,4 \\
\hline & Computer Engineer & 1,6 \\
\hline & Student & 57,7 \\
\hline & Employed in the social sector & 7,6 \\
\hline & Professional & 1,5 \\
\hline & Technician / Engineer & 2,4 \\
\hline & Academic / Educator & 8 \\
\hline & Self-employed & 1,3 \\
\hline & Employed in the public administration & 3 \\
\hline & Other & 7,7 \\
\hline
\end{tabular}

\subsection{The Hypotheses}

The survey delves into the attitudes and behaviours of users with respect to mobile services, sources of influences and innovation. In this paper we investigate whether the identified key attributes of mobile services market evolution have changed in the relatively more mature market context for both mobile users and shoppers. The null $\left(\mathrm{H}_{0}\right)$ and the alternative $\left(\mathrm{H}_{1}\right)$ hypotheses are formulated as follows:

$\boldsymbol{H}_{\boldsymbol{\theta}}$ : Danish mobile users and mobile shoppers attach the same importance to the identified set of attributes 
$\boldsymbol{H}_{1}$ : Danish mobile users and mobile shoppers attach significantly different importance to the identified set of attributes

\section{PRELIMINARY RESULTS AND DISCUSSION}

\subsection{Data analysis}

The majority of respondents own a mobile device. However, it should be mentioned that as the sample includes only Internet users, this finding should be interpreted with caution. The subscription type of mobile contract was chosen by $52.5 \%$ and prepaid by $47.5 \%$. As far as the purpose of mobile use is concerned, the majority of respondents $(55.5 \%)$ use their mobile devices exclusively for private purposes.

Denmark seems to be a comparatively mature market in terms of mobile devices diffusion. $35 \%$ of the respondents reported that they have 4 to 6 years experience with mobile devices, and $28.2 \%$ have more than 6 years of experience. However, in terms of the age of handsets, it was found that the majority of Danish users (49\%) owned their current mobile phone for less than one year. A considerable number of respondents reported that they would buy a new mobile device equipped with better color display (31\%) and PC synchronization to access calendar and emails $(26 \%)$. To our surprise, the least important criterion for buying a new mobile device under study is games $(54 \%)$.

Finally, the majority of the respondents $(55.2 \%)$ reported that their average daily calling time fluctuates between 0 to 5 minutes, and send between 6-20 SMS per week (33.9\%), while most of respondents spend an average of 10 Euros as their monthly mobile phone expenditure $(29 \%)$. This observation corresponds to the official statistics released by the Danish Ministry of Telecommunications and Innovation'. The decrease in daily calling time underlines the need for mobile operators to diversify their service offering and seek for new revenue sources. Moreover, it indicates that mobile users' attitude towards mobile communication as such has changed.

The previous indication may be explained by the responses on what is the most important reason for using mobile devices, which, was found to be the "independence of location and time" $(61.3 \%)$. If this criterion is combined with the decrease in calling time, it indicates that mobile communication is perceived as a mean that enables contacting people and allows "reachability" anywhere, anytime. This emerging trend offers new business opportunities 
to mobile operators for developing customized services that can be bundled with basic communication services. Moreover, other important criteria were "convenience" (47.6\%), the "curiosity" (34.6\%).

The most important criterion for Danish users on selecting a mobile operator was found to be the "low pricing scheme" $(69.5 \%)$, which seems to stimulate the current price competition in communication services. Moreover, "good coverage" was evaluated as the second criterion (39.2\%) and "operator" reputation" as the third (27.8\%).

With respect to $3 \mathrm{G}$ services, their adoption is still at an embryonic stage. Only 8 respondents out of 722 are using $3 \mathrm{G}$ devices. The recently released official statistics on mobile traffic for the second half of 2003 also underpins this finding. The respondents' attitudes towards $3 \mathrm{G}$ services is explored by asking the respondents to choose a statement that best represents them. Whereas $49 \%$ of respondents stated 'no interest', $30 \%$ stated "interested but waiting for new devices and others' reactions". Although part of the respondents are interested in $3 \mathrm{G}$ devices and services, operators' prices and the devices available appear also to influence their attitude.

Furthermore, respondents were asked to report, which mobile services they mainly use. Table 2, provides details on the mobile services usage. However, it should be noted that a considerable percentage of mobile users have not used any of the alternative mobile services in the past ( $85 \%)$.

Table 2. Mobile Services Usage

\begin{tabular}{lll}
\hline \multicolumn{1}{c}{ Services } & Sample \\
\hline Banking and financial services & 30 \\
Shopping & 7 \\
Entertainment & 35 \\
Information and News & 65 \\
Travel booking & 6 \\
Ticket reservation & 29 \\
\hline
\end{tabular}

A major classification between mobile users (i.e., those that have not used any of the services included in Table 2 but have used GPRS data services like MMS and email)) and mobile shoppers (i.e., those that have used at least one mobile service included in Table 2) was made in order to investigate whether there are significant differences between the evaluations provided by each of these groups. In order to determine whether the two identified groups (i.e., mobile users and mobile shoppers) attach equal importance to the investigated variables $t$-Tests were used (Table 3 ).

The results of Tables 3 show that mobile users become more mature. In particular, mobile users and shoppers attach equal importance to the main attributes for mobile services adoption and diffusion, such as pricing, comfort of device, personalization, customer service and security, except of 
the "ease of use interface". These indications offer initial insight to mobile operators on how to develop their marketing strategies and address this market segment.

Table 3. t-Tests Results for Mobile Users versus Shoppers on mobile service attributes

\begin{tabular}{|c|c|c|c|c|c|c|}
\hline & \multicolumn{2}{|c|}{$\begin{array}{c}\text { Means (1: Com. } \\
\text { Unimportant }-5: \mathrm{V} \text {. } \\
\text { Important) }\end{array}$} & \multicolumn{3}{|c|}{$\begin{array}{l}\text { t-Test for Equality of } \\
\text { Means* }\end{array}$} & \multirow[t]{2}{*}{$\begin{array}{l}\text { Hypothesis } \\
\text { Testing }\end{array}$} \\
\hline & $\begin{array}{l}\text { Mobile } \\
\text { Users } \\
210 \\
\end{array}$ & $\begin{array}{l}\text { Mobile } \\
\text { Shoppers } \\
104 \\
\end{array}$ & $\mathrm{t}$ & Sig. & $\begin{array}{l}\mathrm{p}- \\
\text { value }\end{array}$ & \\
\hline $\begin{array}{l}\text { Ease of Use } \\
\text { Interface }\end{array}$ & 2,77 & 2,32 & 2,33 & 0,02 & $\mathrm{p}<0,05$ & $\begin{array}{l}\text { Reject Ho at } \\
\alpha=0,05\end{array}$ \\
\hline Security & 3,08 & 2,8 & 1,03 & 0,3 & $p>0,05$ & Cannot Reject Ho \\
\hline Customer Service & 3,21 & 2,87 & 1,51 & 0,13 & $\mathrm{p}>0,05$ & Cannot Reject Ho \\
\hline Price & 3,86 & 3,67 & 0,74 & 0,46 & $p>0,05$ & Cannot Reject Ho \\
\hline Personalisation & 3,3 & 3,09 & 0,78 & 0,43 & $p>0,05$ & Cannot Reject Ho \\
\hline Comfort of Device & 3,4 & 3,58 & $-0,65$ & 0,51 & $p>0,05$ & Cannot Reject Ho \\
\hline
\end{tabular}

*F-tests indicated equality of variance except of "price" and "personalization" attributes.

\subsection{Evolution path of mobile service market}

According to the results, included in Table 3, "price" remains the most important attribute for both mobile users and shoppers, implying that the cost of using mobile services is critical for their diffusion. It should be noted that this finding is in line with the results of similar studies discussed in section 2, which proved that "high price" constitutes one of the major obstacles towards mobile services diffusion.

Moreover, "comfort of device" was found to be the second most important attribute for both mobile users and shoppers. Mobile users become experienced and informed regarding the various mobile devices available in the market. Therefore, they seek devices that are "easy to use" when accessing mobile services. Apparently, the high sophistication of some devices that incorporate the latest technological advances makes them unattractive to mobile users that prefer easy and simple access to the new services. The recently released official statistics on mobile traffic for the second half of 2003 also underpins this finding, as less than 3500 persons had adopted the only $3 \mathrm{G}$ handset in the Danish market (e.g. the technologically sophisticated Motorola A920).

Furthermore, "personalization" and "customer service" were also found as important attributes for both mobile users and shoppers indicating the maturity of the Danish market where there are more experienced and informed consumers regarding the various mobile service providers and correspondingly the available mobile services. 
On the contrary, "security" and "easy to use interface" were found to be relatively less important attributes for the respondents. As far as "security" is concerned, this does not keep pace with the fact that one of the most important reasons that Internet users do not shop through the Web concerns security issues. In addition, the issue of "easy to use interface" has not become unimportant, but has been "taken for granted" since new mobile handsets include more easy to use interfaces, and routine use tends to diminish the perception of difficulty. However, the difference between mobile users and shoppers, in the importance attached to this attribute may also indicate the users' difficulties on accessing mobile services.

Based on this discussion, it can be concluded that mobile users, which at the same time are Internet users (i.e., they used the Internet to participate in the online survey) are maturing rapidly. They should constitute a target segment for mobile service providers and their strategic marketing planning. Thus, marketing strategies should be customized to the characteristics of this emerging customer group towards satisfying their needs and preferences. For example, the promotional messages' content could underline the "comfort of device" attribute. Furthermore, different marketing strategies could be designed for mobile shoppers increase the usage of mobile services.

\section{CONCLUSIONS, IMPLICATIONS AND FUTURE RESEARCH DIRECTIONS}

Consumer attitudes and behavioral patterns with respect to mobile services' attributes do not significantly differ between mobile shoppers and mobile users. Moreover, the demographic characteristics of these two groups are similar. This indicates that mobile services adoption in the Danish market is accelerating. The process can be enhanced by designing and offering customized marketing mixes tailored to the characteristics and needs of each target group. Mobile service providers can design their strategic marketing planning by using the provided findings in the customer analysis to identify the profile of their current and potential customers. To that end, the present study revealed some critical factors pointing towards acceleration of mobile services' adoption, as well as indicated to marketing experts should exploit the market potential of mobile users. Furthermore, the critical role of consumer behaviour research in the mobile industry was clearly justified.

Another, important parameter that this survey revealed is the different approach of mobile users towards communication services. In particular, mobile users do not spend a lot of time daily on voice services, but use them to contact people and coordinate personal activites. This emerging trend offers new opportunities to mobile service providers to design new mobile 
services that address it. However, there is a strong need to conduct in-depth consumer behaviour surveys focusing on such observations. It is also important to note that the dynamics of perceptions should be investigated by continuous market intelligence generation and dissemination for industry players to both respond to and better anticipate changes in preferences, needs and wants. For this, surveys are an adequate tool, but should be supported by qualitative research methods.

Further research can elaborate on the findings of this exploratory study and develop and test specific research hypotheses within conclusive research designs. For example, focus groups may be used to elaborate on the observation that mobile users do not heavily use communication services but appreciate the feeling of "anytime anywhere reachability" that is being offered. Moreover, experiments can be conducted to test hypotheses such as whether there are significant differences regarding mobile shoppers and users willingness to pay for specific mobile services. This type of research will provide direct managerial implications for mobile service providers and enable them to offer bundles of services for specific market segments. The authors of this paper currently study the social dynamics and price elasticity of two user segments in a field experiment. In the experiment there are a total of 50 people that are allocated new mobile phones and pre-paid SIM cards. The pre-paid card exceeds most peoples' current spending. We investigate how additional resources are allocated to various $\mathrm{m}$-services as well as collect and analyse data in order to identify opportunities for versioning and bundling of mobile service.

\section{ACKNOWLEDGEMENT}

This research was conducted as part of the Mobiconomy project at Copenhagen Business School. Mobiconomy is partially supported by the Danish Research Agency, grant number 2054-03-0004.

\section{REFERENCES}

Anckar, B., and D'Incau, D. 2002, Value creation in mobile commerce: Findings from a consumer survey, J. Information Technology Theory and Application, 4(1): 43-65.

Baker, W. E., and Sinkula, J. M. 2002, Market orientation, Learning orientation and Product Innovation: Delving into the organization's black box, J. Market-Focused Management, 5: 5-23.

Baldi, S., and Thaung, H. P.-P. 2002, The Entertaining way to M-Commerce: japan's Approach to the Mobile Internet - A Model for Europe, Electronic Markets, 12(1): 6-13.

Funk, J. 2001, The Mobile Internet: How Japan Dialled Up and the West Disconnected, Kent, UK: ISI Publications. 
Grönroos, C. 1997, Value-driven Relational Marketing: from Products to Resources and Competencies, J. Marketing Management, 13(5): 407-419.

Hair, J.F.Jr., Bush, R.P. and Ortinau, D.J. 2000, Marketing Research: A Practical Approach for the New Millennium, McGraw-Hill International Editions.

Han, J. K., Kim, N., and Srivastava, R. K. 2002, Market orientation and organizational performance: Is innovation a missing link?, J. Marketing, 62(4): 30-46.

Hurley, R. F., and Hult, G. T. M. 1998, Innovation, market orientation, and organizational learning: An integration and empirical examination, J. Marketing, 62(3): 42-55.

Jaworski, B., Kohli, A. K., and Sahay, A. 2000, Market-driven versus driving markets. $J$. Academy of Marketing Science, 28 (1), 45-54.

Jaworski, B. J., and Kohli, A. K. 1993, Market orientation: Antecedents and consequences, $J$. Marketing, 57(3): 53.

Kinnear, T.C. and Taylor, J.R. 1996, Marketing Research: An Applied Approach, 5th ed., McGraw-Hill, Inc.

Kim, A. J. 2000, Community Building on the Web, Peachpit Press Berkeley CA

Miller, T.W. and Dickson, P.R. 2001, On-line Market Research, Int. J. Electronic Commerce, 5(3): 139-167.

Lyytinen, K., and Yoo, Y. 2002, Research Commentary: The Next Wave of Nomadic Computing, Information Systems Research, 13(4): 377-388.

Pedersen, P. E., Methlie, L., B., and Thorbjørnsen, H. 2002, Understanding mobile commerce end-user adoption: a triangulation perspective and suggestions for an exploratory service evaluation framework. Proccedings of 35 th Annual Hawaii International Conference on System Sciences (HICSS-35), Big Island, Hawaii.

Petrison, L., Blattberg, R.C., and Wang, P. 1997, Database Marketing - Past, Present and Fututre, J. Direct Marketing, 11(4): 109-125.

Ravald, A., \& Grönroos, C. 1996 The value concept and relationship marketing. European Journal of Marketing, 30(2): 19-30.

Rogers, E. M. 1995, Diffusion of Innovations, 4th ed., New York: The Free Press.

Siau, K. and Shen, Z. 2003, Mobile Communications and mobile services, Int. J. Mobile Communications, 1(1/2): 3-14.

Slater, S. F., and Narver, J. C. 2000, The positive effect of a market orientation on business profitability: A balanced replication, J. Business Research, 48(1): 69-73.

Rheingold, H. 2003, Smart Mobs - the next social revolution. Persus Books Group Cambridge MA.

Turban, E., King, D., Lee, J., Warkentin, M. and Chung, M.H. 2002. Electronic Commerce: A Managerial Perspective, Prentice Hall - Pearson Education International.

Urbaczewski, A., Wells, J., and Sarker, S. 2002, Exploring Cultural Differences as a Means for Undertanding the Global Mobile Internet: A Theoretical Basis and Program of Research. Proceedings of 35th Annual Hawaii International Conference on System Sciences (HICSS), Big Island, Hawaii.

Vrechopoulos, A.P., Constantiou, I.D., Mylonopoulos, N, Sideris, I. and Doukidis, G. I. 2002, The Critical Role of Consumer Behavior Research in Mobile Commerce, Int. J. Mobile Communications, 1(3):329-340.

Vrechopoulos, A.P., Constantiou, I.D., Mylonopoulos, N and Sideris, I. 2002, Critical Success Factors for Accelerating Mobile Commerce Diffusion in Europe, Proceedings of the 15th Bled E-commerce Conference, e-Reality: Constructing the e-Economy, Bled, Slovenia. 